\title{
Analytical Approach on Fuel Tank Design for LPG Vehicle
}

\author{
Sul-Ki Choi1), Doo-Sung Baik2)
}

\begin{abstract}
LPG vehicles are advantageous in terms of emissions and fine dust compared to diesel cars, but the power performance is low, and LPDI (Liquified Petroleum Gas Direct Injection) system using turbo direct injection technology is currently being developed. Nevertheless, LPG prices are expected to continue to decline due to the increase in shale gas production, and are expected to contribute to eco-friendly vehicles through the development of commercial LPG vehicles. In 2017, the public can own LPG cars that have been registered for more than 5 years, and the "Safety Management and Business Law of Liquefied Petroleum Gas" was revised. Therefore, from October 2017, the general public has been able to purchase LPG RVs, etc. that use LPG fuel. Since 2018, the Seoul Metropolitan Government has given the first grade to electric hydrogen vehicles, the first to third grades for gasoline, the first to fifth grades for gasoline and gas, and the third to fifth grade for diesel vehicles. Therefore, it is expected that customers will be interested in purchasing LPG vehicles in the future. Moreover, in March 2019, the Ministry of Environment made it possible for the general public to purchase LPG vehicles as part of countermeasures against fine dust. The purpose of this study was to develop an optimal fuel tank in the form of a donut by utilizing the tire space stored in the existing trunk to secure the LPG storage tank in the LPG passenger car as the demand for LPG cars increased. As a development method, structural analysis and destruction experiments according to the internal pressure on the tank were applied.
\end{abstract}

Keywords: LPG (Liquefied Petroleum Gas), Fuel Cylinder, MPI (Multi Point Injection), Eco-Fuel, CNG(Compressed Natural Gas)

\section{Introduction}

After the industrial revolution in the past, the dependence of steam engines and internal combustion engines has grown significantly to gain power. As we entered the year 2000, we were given the opportunity to look back on the excessive human civilization and think about the global environment[1-2]. Nitrogen oxides and soot gas from diesel vehicles have been the main contributors to environmental pollution. Domestic LPG cars are mainly

Received(January 14, 2020), Review Result(1st: February 19, 2020, 2nd: April 09, 2020), Accepted(May 27, 2020)

1) (Ph.D candidate) 31498 Dept. of Energy \& Climate Environment Fusion Technology, Hoseo Univ., Asan, Korea

email: k8090049@naver.com

2) (Professor, Corresponding Author) 11159 Dept. of Mechanical Engineering, Daejin Univ., Pocheon, Korea email: dsbaik@daejin.ac.kr 
developed for vehicles with a lot of driving distances, such as taxis, and technologies are being developed to improve fuel efficiency by introducing turbo mounting, direct injection, or downsizing. In addition, atmospheric problems, including fine dust, which have become serious due to the indiscriminate use of fossil fuels, are becoming a hot topic. Recently, in 2019, the Low Emission Zone has been set up to suggest the operation of vehicles with low-grade 5 to 6- grade cars at the Green Traffic Promotion Zone, the fourth gate of the Seoul city center. The target vehicles are diesel vehicles before 2019 and gasoline vehicles before 2000. Currently, about 410,000 vehicles are in the target vehicles. As the LPG passenger car deregulation legislation "Law for Safety Management and Revision of Liquefied Petroleum Gas" passed the National Assembly, restrictions on LPG fuel use for transportation were abolished from March 26, 2019, and the public can buy and sell LPG vehicles. If the restrictions on LPG fuel use are fully eased, the number of LPG cars will increase to 2,102,000 in 2019 and 2,820,000 in 2030. As a result, by 2030, ultrafine dust will be reduced by up to 48 tons. And it is estimated that by including the causative agent of secondary generated fine dust, the fine dust will be reduced by up to 4,986 tons. It was estimated that the cost of environmental damage would decrease by about 400 billion won per year[3-4].

The biggest advantage of LPG vehicles is the relatively low maintenance cost, and the average price per liter of gasoline or diesel is $1300 \sim 1400$ won. In addition to the low LPG price, LPG has less pollutants emitted[5-8]. On the other hand, the current charging station infrastructure is as low as $1 / 10$ of that of gasoline or diesel gas stations, which is inconvenient and has low output. In addition, since the LPG tank is currently stored in the trunk, the storage space is quite small[9]. LPG vehicles have these disadvantages, but it is necessary to continuously conduct research and development considering the economic and environmental aspects of the future.

In this study, to convert a gasoline or gasoline car into an LPG vehicle, space for the fuel tank must be secured. To develop an LPG fuel tank to be installed in a space provided with a spare tire existing in the trunk, gas safety is ensured to secure the maximum space in the trunk. In order to secure reliability by completing a prototype for the LPG fuel tank for a passenger car by conducting a first safety test and a second actual destruction test through a commercial computer program. 


\section{Numerical Analysis and Experiment for Fuel Tank}

\subsection{Numerical Analysis}

In order to develop an LPG fuel tank to be installed in a spare tire spare space in a passenger car trunk, numerical analysis was performed using commercial code ANSYS through computer simulation. [Fig. 1] was prepared using a CAD drawing of a fuel tank with a spare tire shape. [Fig. 2] performed calculations on the 75,000 square lattices needed for the numerical analysis. In the case of $8.5 \mathrm{MPa}$, total strain, elastic strain, and stress are shown in [Fig. 11], [Fig. 12], and [Fig. 13], respectively. In particular, the relationship between strain and stress graph in [Fig. 14] shows that the vertical stress linearly changes to an elastic section up to 0.3. However, after that, it was confirmed that the container structure itself was deformed and damaged.

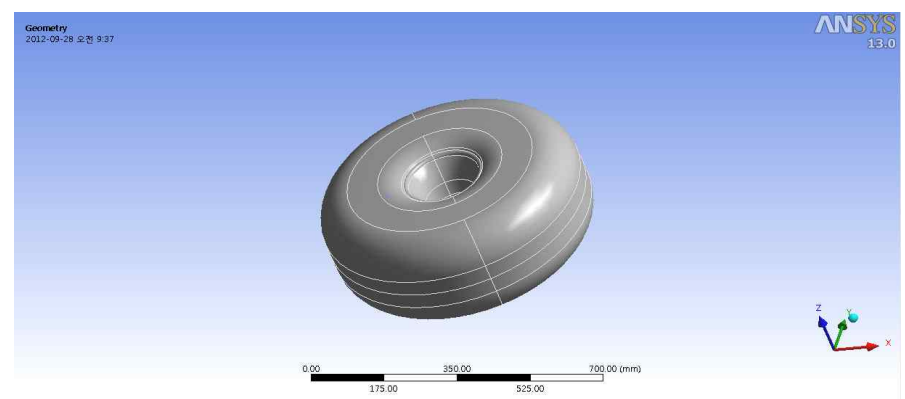

[Fig. 1] Configuration of Fuel Tank for Spare Tire

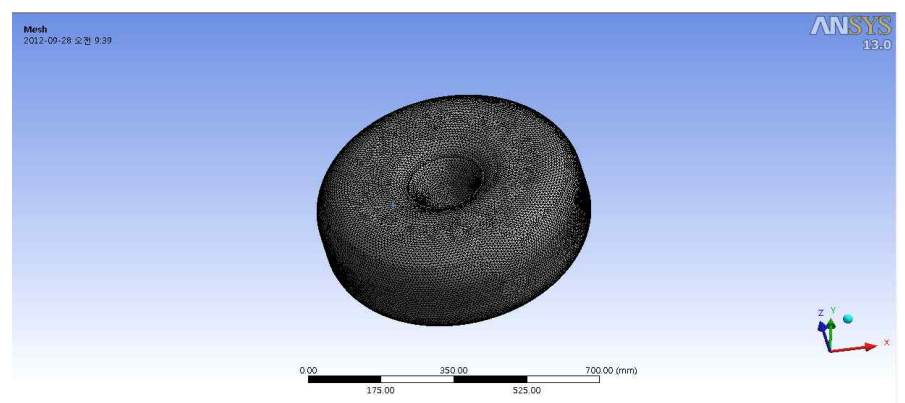

[Fig. 2] Mesh Generation (7,5000)

The material of the fuel tank was SG365, and the non-linear structural analysis was performed while gradually increasing the internal pressure from $1.8 \mathrm{MPa}$ to $5.0 \mathrm{MPa}$, $6.0 \mathrm{MPa}$, 
$7.5 \mathrm{MPa}$, and 8.5 MPa. [Fig. 3], [Fig. 4], and [Fig. 5] show the total strain, elastic strain, and stress for the inner pressure of $1.8 \mathrm{MPa}$.

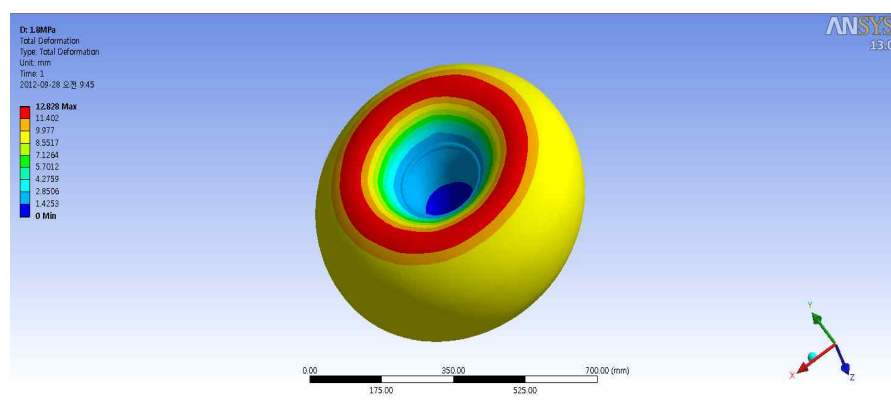

[Fig. 3] Total Deformation (Internal Pressure 1.8MPa)

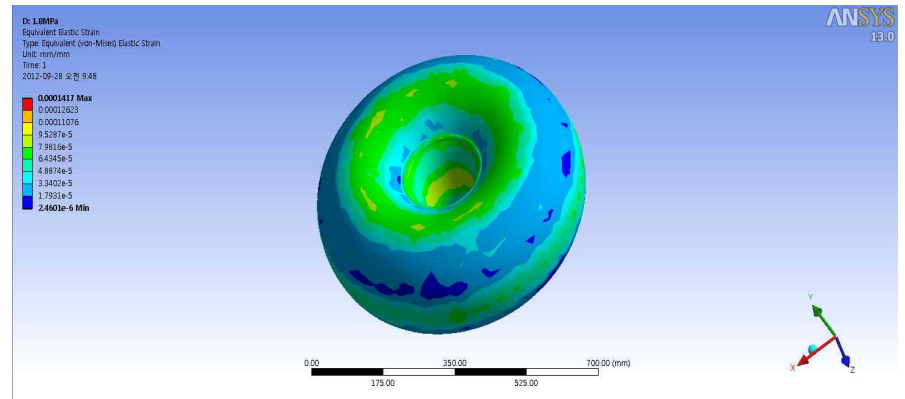

[Fig. 4] Elastic Strain (Internal Pressure 1.8MPa)

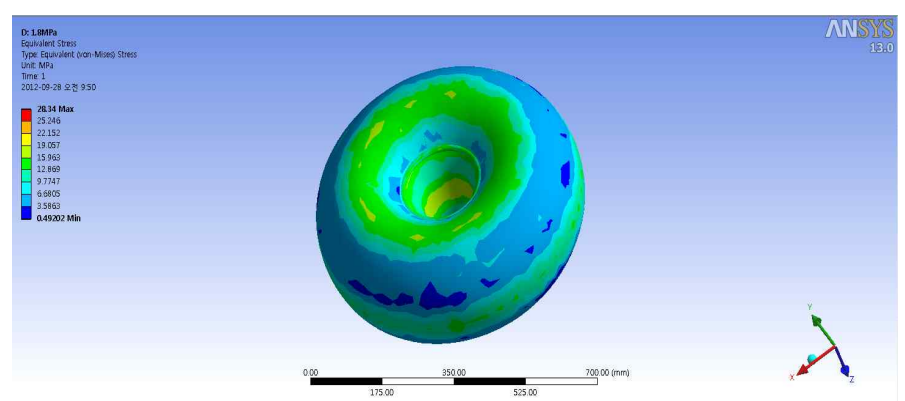

[Fig. 5] Stress (Internal Pressure 1.8MPa)

[Fig. 7], [Fig. 8], and [Fig, 9] show the total strain, elastic strain, and stress for $7 \mathrm{MPa}$ internal pressure, respectively. Here, the relationship between strain and stress increased linearly until the internal pressure was $7 \mathrm{MPa}$ (See [Fig. 6] and [Fig. 10]) 


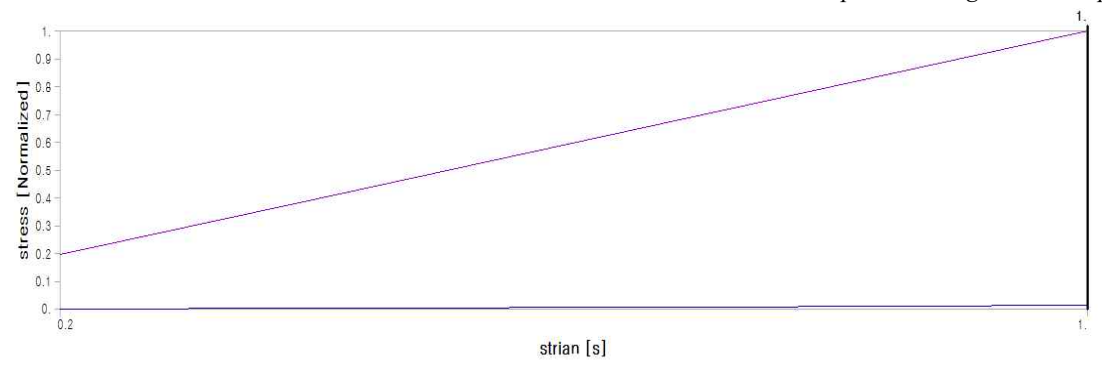

[Fig. 6] Stress-Strain (Internal Pressure 1.8MPa)

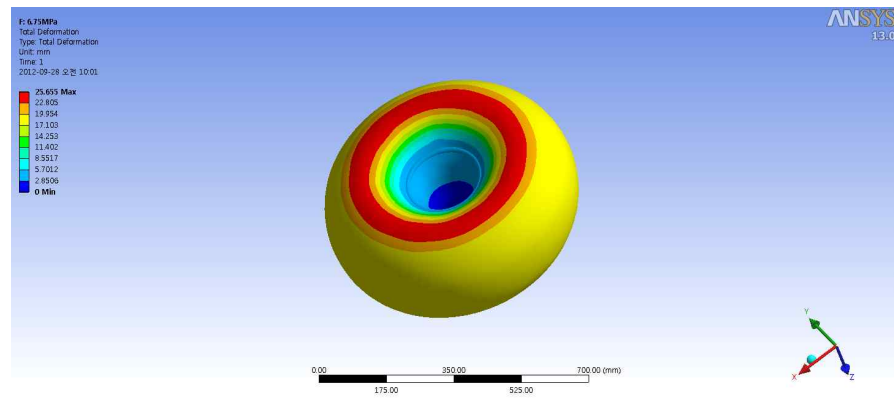

[Fig. 7] Total Deformation (Internal Pressure 7MPa)

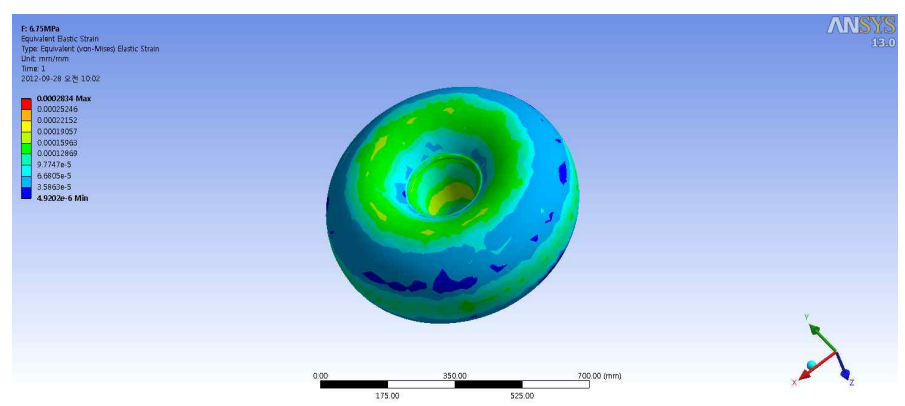

[Fig. 8] Elastic Strain (Internal Pressure 7MPa)

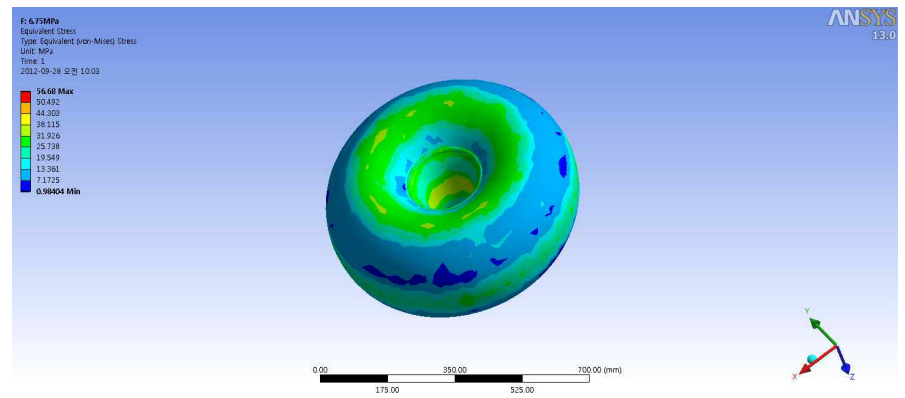

[Fig. 9] Stress (Internal Pressure 7MPa) 


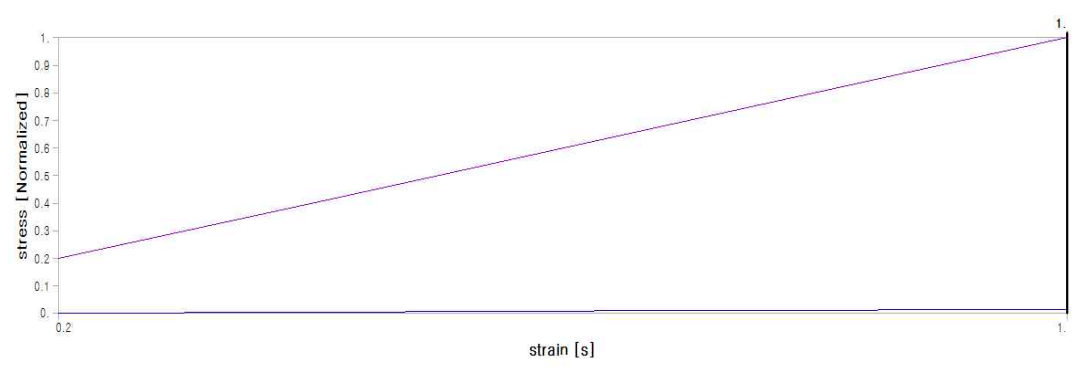

[Fig. 10] Stress-Strain (Internal Pressure 7MPa)

In the case of $8.5 \mathrm{MPa}$, total strain, elastic strain, and stress are shown in [Fig. 11], [Fig. 12], and [Fig. 13], respectively. In particular, the relationship between strain and stress graph in [Fig. 14] shows that the vertical stress linearly changes to an elastic section up to 0.3. However, after that, it was confirmed that the container structure itself was deformed and damaged.

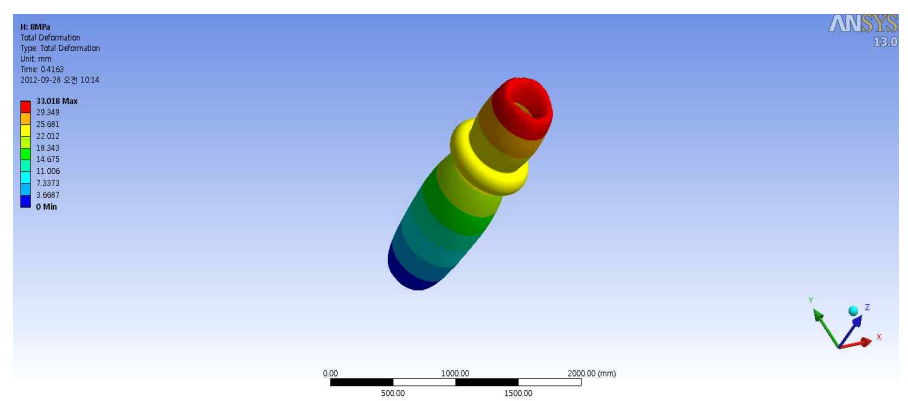

[Fig. 11] Total Deformation (Internal Pressure 8.5MPa)

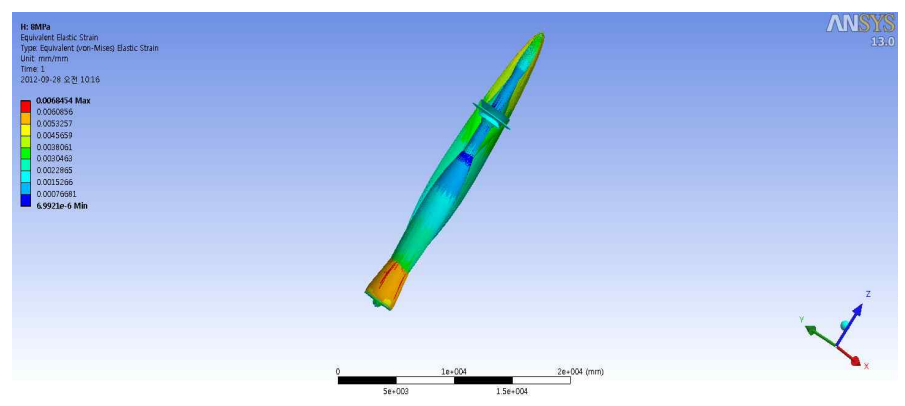

[Fig. 12] Elastic Strain (Internal Pressure 8.5MPa) 


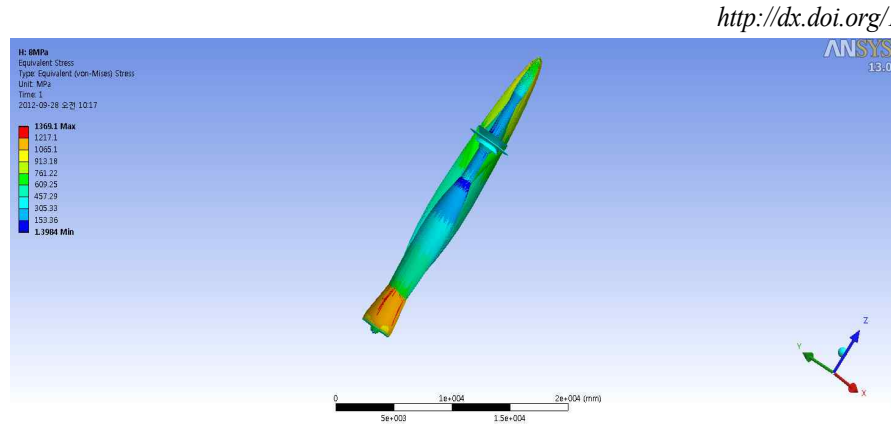

[Fig. 13] Stress (Internal Pressure 8.5MPa)

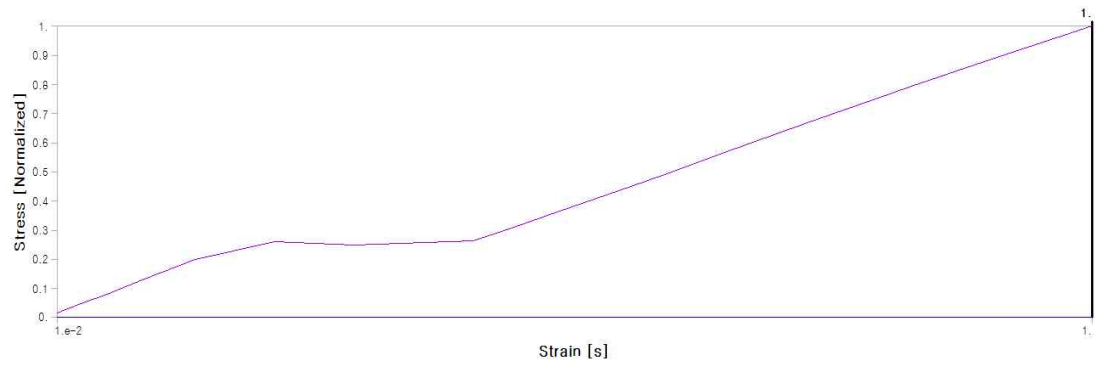

[Fig. 14] Stress-Strain (Internal Pressure 8.5MPa)

\subsection{Experiment for Fuel Tank}

In developing the LPG gas tank shape, it is important to ensure safety, and a flame exposure test has been conducted. In order to check the gas filling state by combining the donut tank and the gas valve, LPG gas and water density were compared, and about $80 \%$ of the water was filled in a 72-liter tank to confirm the actual capacity of 72-liter, and then the LPG gas was completely charged into the container. In the flame exposure test, the LPG tank container was heated from outside to check the pressure in the tank. As the flame progresses and a certain period of time increases, the pressure in the tank container increases, and the fusible (lead) attached to the gas valve melts, and the gas is ejected and the safety valve in the gas valve is activated. See [Fig. 15].

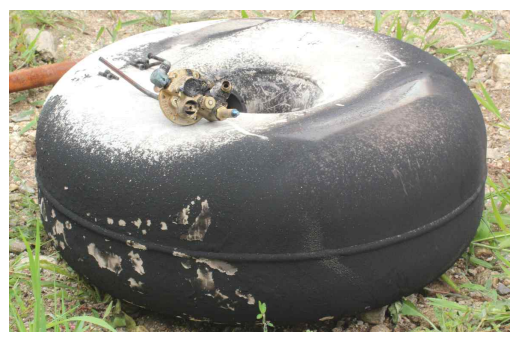

[Fig. 15] Toroidal Shape of LPG Fuel Tank 


\section{Results}

In order to realize the shape of the LPG fuel tank, ANSYS computer commercial code was applied to perform structural analysis on an annular container of 72-liters and material SG 365 . The internal pressure was presented as a boundary condition to visualize the stress and elastic deformation according to the internal pressure, and the relationship between stress and elastic deformation was presented graphically. The internal pressure was set to a boundary condition from 1.8 $\mathrm{MPa}$ to $8.5 \mathrm{MPa}$. The linear relationship between stress and elastic strain was confirmed up to $7.5 \mathrm{MPa}$, and when the internal pressure was $8.5 \mathrm{MPa}$, the stress was linearly changed to 0.3 , but after 0.3 , the structure was deformed due to the breakage of the container.

\section{Conclusion}

In order to develop a container capable of withstanding the internal pressure of LPG fuel for material SG365, in order to develop a 72-liter annular fuel tank that can be installed on the LPG passenger car spare tire, the relationship between stress and strain to determine the maximum elastic strain using commercial computer codes (Linear relationship) was confirmed. In addition, since gas container safety is important, an important flame exposure test was conducted among gas safety test items. Through numerical analysis and testing, the maximum pressure that a 72-liter annular container can withstand is $7.5 \mathrm{MPa}$, and considering $30 \%$ safety, it is judged that it can withstand $5.0 \mathrm{MPa}$ internal pressure.

\section{References}

[1] S. Goto, D. Lee, N. Harayama, F. Honjo, H. Honma, Y. Wakao and M. Mori, Development of LPG SI and CI Engines for Heavy Duty Vehicles, Fisita World Automotive Congress, (2000), June 12-15; Seoul Korea.

[2] A. Sobiesiak, M. W. Hoag, M. Battoei-Avarzaman, Injector Durability and Emissions from Liquid LPG Port Injected Spark Ignition Engine, SAE Powertrain \& Fluid Systems Conference \& Exhibition, (2003), DOI: https://doi.org/10.4271/2003-01-3090

[3] T. Yamauchi, T. Wakisaka, Computation of the hollow-Cone sprays from high pressure swirl injector for a gasoline direct injection SI engine, SAE Technical paper, (1996), 962016. https://www.sae.org/publications/technical-papers/content/962016/ 
[4] M. K. Balki, C. Sayin, M. Sarkaya, Optimization of the operating parameters based on Taguchi method in an SI engine used pure gasoline, ethanol and methanol, Fuel, (2016), Vol.180, pp.630-637, DOI: https://doi.org/10.1016/j.fuel.2016.04.098

[5] A. K. Agarwal, D. K. Srivastava, A. Dhar, R. K. Maurya, P. C. Shukla, A. P. Singh, Effect of fuel injection timing and pressure on combustion, emissions and performance characteristics of a single cylinder diesel engine, Fuel, (2013), Vol.111, pp.374-383, DOI: https://doi.org/10.1016/j.fuel.2013.03.016

[6] K. Kim, J. Oh, S. Kim, Lower particulate matter emissions with a stoichiometric LPG direct injection engine, Fuel, (2017), Vol.187, pp.197-210, DOI: https://doi.org/10.1016/j.fuel.2016.09.058

[7] C. Myung, S. Park, Exhaust nanoparticle emissions from internal combustion engines, International Journal of Automotive Technology, (2012), Vol.13, No.1, pp.91-97.

[8] S. Choi, Doo-Sung Baik, A Study on The Change of Output in The LPG Retrofitted Car With LPG, Convergence Research Letter, (2018), Vol.5, No.2, pp.1101-1104.

[9] Sul-ki, Choi, Doo-Sung Baik, A Study on Toroidal Bombe in LPG Vehicle, Convergence Research Letter, (2019), Vol.5, No.3, pp.711-714. 